\title{
Formation of linear plasmid multimers promoted by the phage lambda Red-system in lon mutants of Escherichia coli
}

\author{
E. MYTHILI ${ }^{1}$ and K. MuniYAPPA ${ }^{1,2 *}$ \\ ${ }^{1}$ Department of Biochemistry and ${ }^{2}$ Centre for Genetic Engineering, Indian Institute of Science, Bangalore 560012, \\ India
}

(Received 16 November 1992; revised 1 March 1993; accepted 19 April 1993)

\begin{abstract}
We report here the formation of plasmid linear multimers promoted by the Red-system of phage lambda using a multicopy plasmid comprised of lambda red $\alpha$ and $r e d \beta$ genes, under the control of the lambda $c 1857$ repressor. Our observations have revealed that the multimerization of plasmid DNA is dependent on the red $\beta$ and $\operatorname{rec} A$ genes, suggesting a concerted role for these functions in the formation of plasmid multimers. The formation of multimers occurred in a $\operatorname{rec} B C D^{+} s b c B^{+} x t h A^{+}$lon genetic background at a higher frequency than in the isogenic lon ${ }^{+}$host cells. The multimers comprised tandem repeats of monomer plasmid DNA. Treatment of purified plasmid DNA with exonuclease III revealed the presence of free double-chain ends in the molecules. Determination of the size of multimeric DNA, by pulse field gel electrophoresis, revealed that the bulk of the DNA was in the range 50-240 kb, representing approximately 5-24 unit lengths of monomeric plasmid DNA. We provide a conceptual framework for Red-system-promoted formation and enhanced accumulation of plasmid linear multimers in lon mutants of $E$. coli.
\end{abstract}

\section{Introduction}

Replication of the phage lambda chromosome is under temporal control: an early transitory phase characterized by the formation of circular monomers is followed by a robust second phase, the rolling circle mode of replication (Skalka, 1977). In the absence of normal replication DNA concatemers produced via recombination are required for the development of phage lambda, because they serve as intermediates in the packaging process (Stahl et al., 1972; Stahl \& Stahl, 1974). Genetic studies have illustrated linkage of recombination functions and DNA synthesis during phage maturation. Two activities, gam and red, specified by phage lambda are necessary for the rolling circle mode of replication (Enquist \& Skalka, 1973). gam function is essential for the inhibition of host RecBCD nuclease and thereby renders protection to intermediates and products generated by replication (Unger \& Clark, 1972; Karu et al., 1975; Greenstein \& Skalka, 1975). The red genes, $r e d \alpha$ and $r e d \beta$, promote homologous genetic recombination but their role in the rolling circle mode of replication is unclear. Evidence for the role of red genes in growth and development of phage lambda is derived

*Author for correspondence. Tel. +91 (80) 344411 ext. 309; fax $+91(80) 341683$. from two fronts: in a series of elegant studies, F. W. Stahl and his colleagues have shown that in an infection, when replication was inhibited, all the progeny molecules had undergone homologous recombination (Stahl et al., 1972). A. Skalka and her colleagues showed that the packaging of phage lambda DNA was defective in red gam mutants plated on recombination-deficient $E$. coli strains (Enquist \& Skalka, 1973).

Multimerization of plasmids has been used as a paradigm to study homologous genetic recombination in both pro- and eukaryotic systems (Bedbrook \& Ausubel, 1976; Symington et al., 1983; Harashima et al., 1989). R. Kolodner and his colleagues have shown that oligomerization of plasmids and their subsequent resolution into monomers in bacteria is controlled by both cis- and trans-acting factors that participate in homologous recombination (James et al., 1982, 1983; Doherty et al., 1983). Most recently, A. Cohen and his colleagues discovered the occurrence of large amounts of linear multimers of plasmids in $r e c B C D, s b c B, s b c C$ and $\operatorname{rec} B C$ $s b c A$ host strains and accordingly have proposed an hypothesis to account for the mutual dependence of plasmid multimer synthesis and recombination by the RecE-, RecF- and Red pathways (Cohen \& Clark, 1986; Silberstein \& Cohen, 1987; Nussbaum \& Cohen, 1988; Berger \& Cohen, 1989). Interestingly, however, the mechanism of linear multimer formation is different 
from that of normal plasmid replication and maintenance (Yarmolinsky \& Sternberg, 1988; Niki et al., 1990).

The role of phage lambda red genes, at the molecular level, in the formation of concatemers and thus in growth and development is unclear. The observation that $\mathrm{RecE}$ and $\mathrm{RecF}$ pathways play a prominent role in plasmid multimer synthesis (Berger \& Cohen, 1989; Kusano et al., 1989) and the functional similarity among RecE- and Red-pathways prompted us to seek physical evidence for the role of $r e d \alpha$ and $r e d \beta$ in plasmid multimer formation. In addition, we are interested in identifying gene(s) and their products involved in the regulation of homologous genetic recombination in vivo. To our knowledge such an approach has never been taken before. Our study on the possible role of red genes in multimer formation via recombination stems from a novel observation that the joining of terminal ends ( $\cos$ to $\cos$ joining) of the phage lambda chromosome in vitro is promoted by $\beta$ protein (Muniyappa \& Radding, 1986). Results presented in this paper show that linear multimer formation is maximal in lon mutants of $E$. coli which are otherwise wild-type for the RecBCD, ExoI and ExoIII proteins, and we propose a model to account for their enhanced accumulation.

\section{Methods}

Bacterial strains, plasmids and growth conditions. E. coli strains used in this study are listed in Table 1. P1 lysates were prepared as described by Miller (1972) and transductions were done as described by Willets et al. (1969). The plasmid pSJS6, a gift from Drs S. J. Sandler and A. J. Clark of the University of California, Berkeley, CA, USA, is a derivative of pBR322 (Sandler \& Clark, 1990). pSJS6 carries a fragment of lambda chromosome containing the red genes that encode the functions for general genetic recombination of phage lambda: exonuclease and $\beta$ protein, and a ninL4 deletion in the gam gene (Fig. 1 ). The expression of exonuclease and $\beta$ protein is from the $P_{L}$ promoter of phage lambda, under the control of the $c 1857$ repressor.

Bacterial strains carrying plasmids were derived by transformation using the $\mathrm{CaCl}_{2}$ method and stored at $-20{ }^{\circ} \mathrm{C}$ in $50 \%(\mathrm{v} / \mathrm{v})$ glycerol. Transformation of plasmid DNA into $E$. coli was carried out as described by Maniatis et al. (1982). Bacterial cells containing plasmids were grown in L-broth or on L-plates at the indicated temperatures (Luria \& Burrous, 1957). Ampicillin and tetracycline were added to growth media at concentrations of $100 \mu \mathrm{g} \mathrm{ml}^{-1}$ and $25 \mu \mathrm{g} \mathrm{ml}^{-1}$, respectively.

Table 1. E. coli strains used

\begin{tabular}{lcc}
\hline \hline Strain & \multicolumn{1}{c}{ Genotype } & Source \\
\hline AB1157 & $\mathrm{F}^{-}$thr-1 ara-14 leuB6 $\Delta($ gpt-proA $) 62$ & Laboratory \\
& lacY1 tsx33 supE44 galK2 hisG4 rspL31 & collection \\
& kdgK51 xyl-5 mtl-5 argE3 thi-1 & \\
JC12578 & $\mathrm{F}^{-}$thr-1 thi-1 lacY1 galK2 ara-14 xyl-5 & A. J. Clark \\
& mtl-5 proA2 his4 rspL31 tsx33 supE44 & \\
& $\Delta($ srlR-recA $306:: \operatorname{Tn} 10$ recF146 uvrA6 & \\
JK7 & As AB103 & R. Jayaraman \\
KM102 & As AB1157 but recA56 srl-300 Tn10 & This Study \\
\hline \hline
\end{tabular}

Test for cell viability. Bacterial cells from a fresh transformant colony were grown in L-broth, containing antibiotic, to mid-exponential phase at $30^{\circ} \mathrm{C}$ and then at $42{ }^{\circ} \mathrm{C}$ for $3 \mathrm{~h}$. At regular time intervals aliquots were taken, diluted appropriately and plated on L-plates to determine the number of viable cells. Cell number (density) was determined by monitoring the optical density at $600 \mathrm{~nm}$.

Purification of total plasmid DNA. Bacterial cells were grown in $3 \mathrm{ml}$ cultures at $30^{\circ} \mathrm{C}$ to mid-exponential phase and then transferred to $42^{\circ} \mathrm{C}$ for $3 \mathrm{~h}$ to facilitate the derepression of red genes. Total plasmid DNA was isolated from the cell-free lysates as described by Clark \& Cohen (1986) and Silberstein et al. (1990). Briefly, the lysed cell suspension was centrifuged to pellet the cell debris and the supernatant was treated with RNAase $(50 \mu \mathrm{g})$ for $30 \mathrm{~min}$. The sample was then extracted with phenol/chloroform/isoamyl alcohol solution $(25: 24: 1$, by vol.). The DNA in the aqueous phase was precipitated with ethanol.

Plasmid DNA was also prepared from cell-free lysates by $\mathrm{CsCl}-$ ethidium bromide density centrifugation (Maniatis et al., 1982). Linear plasmid DNA was present exclusively in the upper band in this gradient system. A major fraction of total plasmid DNA from lon mutant strains was present in the upper band. Samples of the plasmid DNA preparation were loaded onto a $0.5 \%$ agarose gel and electrophoresed in $89 \mathrm{~mm}$-Tris/borate, $2 \mathrm{~mm}$-EDTA (pH 8.3) at $2 \mathrm{~V} \mathrm{~cm}^{-1}$ for $20 \mathrm{~h}$. The gel was stained with ethidium bromide and photographed.

Southern blotting. Total plasmid DNA preparations electrophoresed on agarose gels were transferred to Nytran membrane as described by Southern (1975). The membrane was probed with a radiolabelled $E c o$ RI fragment containing lambda DNA (Fig. 1). For estimation of relative amounts of multimeric DNA the autoradiograms were scanned with an LKB Ultroscan XL densitometer and the data analysed using an LKB Gelscan XL.

Restriction enzyme digestion. Total plasmid DNA was digested in a standard assay buffer with 2 units of SalI, EcoRI or XhoI, where indicated, as suggested by the manufacturer. The nicking of pSJS6 DNA by SalI and pBR322 DNA by EcoRI was done under standard assay conditions in the presence of $0 \cdot 1 \mu \mathrm{g}$ ethidium bromide $\mathrm{ml}^{-1}$ and the reaction was carried out in dark (Rould et al., 1992).

Exonuclease III digestion. Total plasmid DNA obtained from JK 7 $\left(\right.$ recA56 lon $^{+}$) and KM102 ( ec $^{+}$lon) strains harbouring pSJS6 was purified by $\mathrm{CsCl}$ density centrifugation and treated with 20 units of $E$. coli exonuclease III at $37^{\circ} \mathrm{C}$ for $15 \mathrm{~min}$ in a buffer containing $60 \mathrm{~mm}$ Tris/ $\mathrm{HCl}, 0.6 \mathrm{~mm}-\mathrm{MgCl}_{2}$ and $1 \mathrm{~mm}$-dithiothreitol $(\mathrm{pH} 8.0)$. The reaction was terminated by adding EDTA to a final concentration of $25 \mathrm{mM}$. Individual samples were electrophoresed on a $0.5 \%$ agarose gel as described above.

Pulse field gel electrophoresis. Total plasmid DNA extracted from the lon mutant (KM102), harbouring pSJS6, which had been subjected to the temperature shift from $30^{\circ} \mathrm{C}$ to $42^{\circ} \mathrm{C}$ for $3 \mathrm{~h}$, was isolated by $\mathrm{CsCl}$ density gradient centrifugation. A $2 \mu \mathrm{g}$ sample of this DNA was suspended in molten agarose, and a solidified agarose block was placed in a $0.9 \%$ agarose gel. Electrophoresis was done in a LKB Pulsaphor electrophoresis unit with hexagonal electrodes, in a buffer containing $45 \mathrm{~mm}$-Tris/borate and $1 \mathrm{~mm}$-EDTA ( $\mathrm{pH} \mathrm{8.3)}$ ), at a constant voltage of $6 \mathrm{~V} \mathrm{~cm}^{-1}$ at $20^{\circ} \mathrm{C}$ for $24 \mathrm{~h}$. The pulse time was as follows: $20 \mathrm{~s}$ east-towest and $20 \mathrm{~s}$ north-to-south. Multimers of full-length lambda DNA was used as a standard marker. The DNA was transferred to a Nytran membrane and analysed by Southern hybridization as described above.

Preparation of deletion mutants by Bal31 nuclease digestion. pSJS6 DNA $(5 \mu \mathrm{g})$ linearized by $\mathrm{SalI}$ was incubated at $30^{\circ} \mathrm{C}$ with Bal31 nuclease (10 units) in a reaction mixture $(50 \mu \mathrm{l})$ containing $50 \mathrm{~mm}$ Tris/ $\mathrm{HCl}\left(\mathrm{pH} 7.5\right.$ ), $10 \mathrm{~mm}-\mathrm{CaCl}_{2}, 10 \mathrm{mM}-\mathrm{MgCl}_{2}, 0.5 \mathrm{M}-\mathrm{NaCl}$ and $50 \mu \mathrm{g}$ bovine serum albumin $\mathrm{ml}^{-1}$. At different time intervals aliquots of DNA were removed from the reaction mixture and heated at $75^{\circ} \mathrm{C}$ for 
$10 \mathrm{~min}$. The DNA was precipitated by ethanol. The resuspended DNA was treated with Klenow and NTPs to create blunt ends and recircularized as described by Maniatis et al. (1982). The recircularized plasmid DNA was transformed into $E$. coli as described above. DNA was isolated from individual colonies and then digested with BamHI to map the extent of the deletion.

\section{Results}

Red-system-promoted formation of plasmid linear multimers

Previous studies have revealed that the synthesis of plasmid multimers is dependent on the cellular recombination machinery (reviewed in: Smith, 1988; Clark \& Low, 1988; Mahajan, 1988). This prediction has been substantiated by a number of studies using recombination-defective strains of $E$. coli (Cohen \& Clark, 1986; Kusano et al., 1989). To elucidate the possible role of recombination enzymes of the Redsystem of phage lambda in plasmid multimerization, we used plasmid pSJS6 which contains the replicon of the plasmid pBR322 that codes for ampicillin resistance (Fig. 1). This plasmid also contains the red genes, red $\alpha$ (exo) and $\operatorname{red} \beta$ (bet), expressed from the lambda $\mathrm{P}_{\mathrm{L}}$ promoter, under the control of the $c 1857$ repressor. The expression of red genes was accomplished by transferring the cultures harbouring pSJS6 from $30^{\circ} \mathrm{C}$ to $42^{\circ} \mathrm{C}$. Such a treatment results in transient expression of Lon protease, which has been shown to regulate the stability of a number of proteins specified by the host and lambda phage (Gottesman, 1989).

We tested the role of lon function in the production of plasmid linear multimers promoted by red genes in the isogenic E. coli strains AB1157 and KM102; the latter was obtained by transduction of AB1157 by bacteriophage P1. We used pSJS6 Form I DNA prepared from a

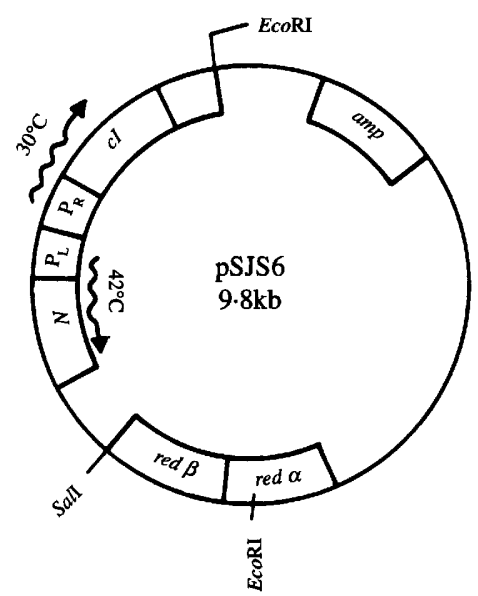

Fig. 1. Structure of plasmid pSJS6. The double line indicates genes that are relevant to this study and the region marked $a m p$ is the gene for ampicillin resistance. For other details see Methods. rec $A$ host to transform strains $\mathrm{AB} 1157$ and $\mathrm{KM} 102$. Single colony isolates containing plasmids were selected by plating the transformed cells in the presence of ampicillin and tetracycline, where required. For the preparation of DNA they were grown in L-broth, containing the above antibiotics, at $30^{\circ} \mathrm{C}$ to midexponential phase and then transferred to $42^{\circ} \mathrm{C}$ for $3 \mathrm{~h}$ to facilitate derepression of red genes. The plasmid DNA was isolated from several independent transformants and analysed by agarose gel electrophoresis. We detected large amounts of abnormally high molecular mass (hmm) DNA on agarose gels. The pattern of one such DNA preparation obtained from identical density of cells, is illustrated in Fig. 2. In addition to the expected topological forms of DNA, such as Form I, Form II and Form III, these preparations contained several DNA species of larger size. To exclude the possibility that hmm DNA represents different topological forms of monomeric DNA, we treated total pSJS6 plasmid DNA with SalI in the presence and in the absence of ethidium bromide. Digestion of duplex DNA with a restriction endonuclease, in the presence of ethidium bromide, results in nicking of DNA (Rould et al., 1992). pSJS6 plasmid DNA has a single recognition site for SalI and introduction of a nick by $S a l$ I should convert the supercoiled forms into an open circular form. Treatment of pSJS6 DNA obtained from rec $A^{+} \operatorname{lon}^{+}$(AB1157) and recA $A^{+}$lon $^{-}$(KM102) hosts with SalI in the presence of ethidium bromide partially converted Form I DNA into Form II DNA. Nonetheless, the slow-migrating bands of plasmid DNA which persisted do not represent topoisomers of Form I DNA (see below). The absence of such a conversion of slow-migrating plasmid DNA suggested that these molecules are multimers of pSJS6 monomeric DNA. This conclusion is supported by the cleavage of pSJS6 plasmid DNA by Sall, which produced a single species of Form III DNA (Fig. 2). These data, therefore, indicate that the hmm DNA contains tandem repetitions of the monomer unit of pSJS6 plasmid DNA.

To confirm that the hmm DNA is indeed pSJS6 plasmid DNA, and not chromosomal DNA, the identity of the DNA was determined by Southern blotting and hybridization using a radiolabelled EcoRI DNA fragment derived from pSJS6 plasmid DNA (Fig. 1). As shown in Fig. 2(b), the hybridization pattern clearly corresponded with that of the gel stained with ethidium bromide. The relative amounts of multimers produced by the Red system was dependent on the host lon function. For instance, mutations in lon increased the extent of accumulation of plasmid multimers (Fig. 2). To test whether the $\operatorname{rec} \mathrm{A}^{+}$function was essential for the Redsystem-promoted plasmid multimerization, we transformed pSJS6 plasmid DNA into JC12578, a recA null strain derived from AB1157. The extent of formation of 

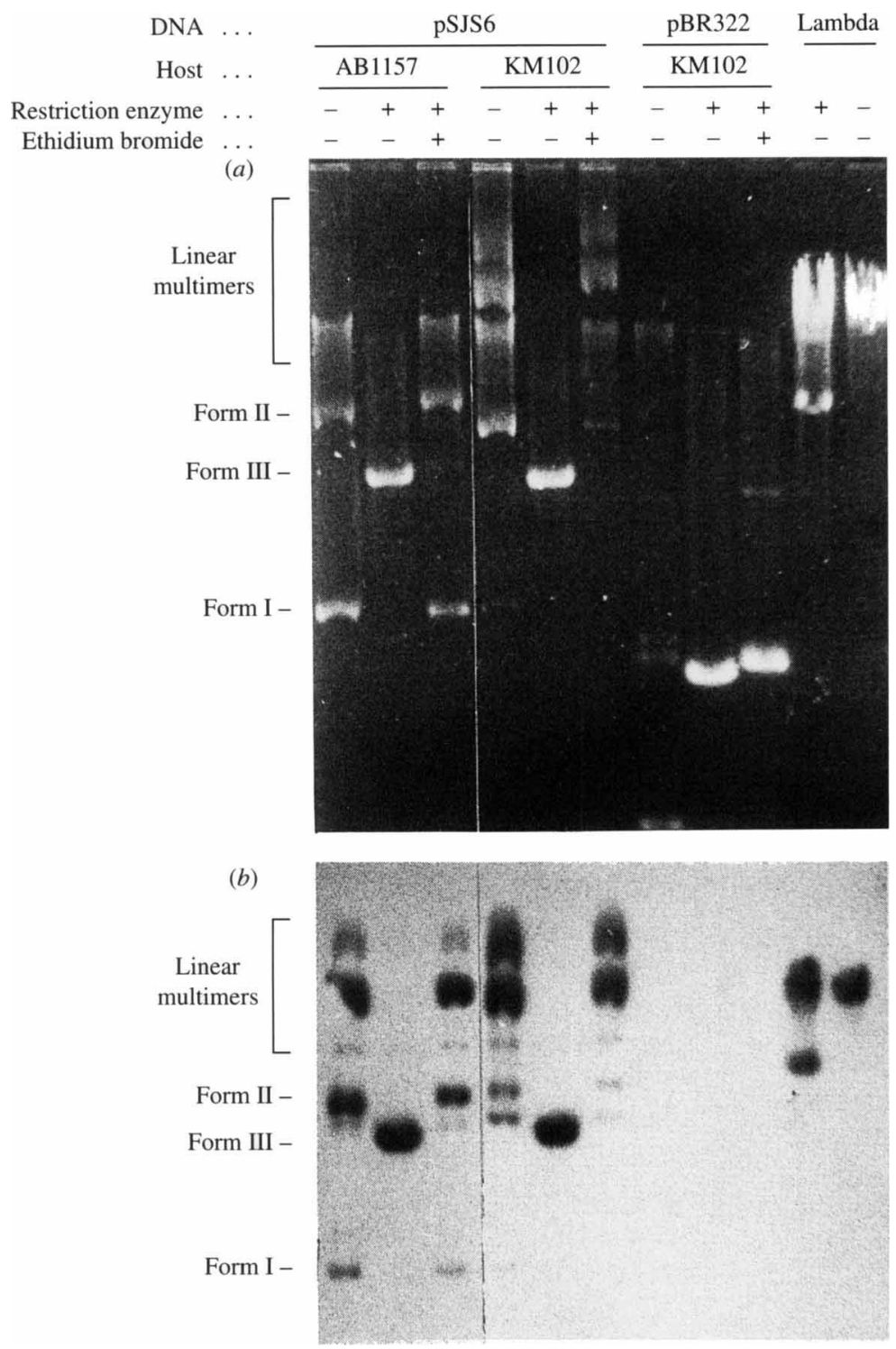

Fig. 2. Accumulation of plasmid multimers is maximal in lon mutants of E. coli. (a) Electrophoretic analysis of plasmid DNA. Total plasmid DNA was purified from the designated genotypes harbouring pSJS6 and pBR322 and analysed on an agarose gel as described in Methods. The gel was stained with ethidium bromide and photographed. (b) The DNA in the above gel was transferred to a Nytran membrane and visualized by Southern hybridization with a radiolabelled $E c o$ RI fragment as a probe (Fig. 1). The location of different topological forms of plasmid monomeric DNA is indicated: Form I DNA, negatively superhelical DNA; Form II, nicked closed circular DNA; Form III, linear duplex DNA. The lambda chromosome was digested with $X h o I$. hmm DNA was 100-fold less than that obtained in rec $A^{+}$ host cells, suggesting a requirement for RecA protein (data not shown). These studies on the formation of hmm DNA in vivo corroborate an earlier finding of the concerted action of the RecA and $\beta$ proteins in the formation of joint molecules in vitro (Muniyappa \& Radding, 1986). More importantly, we observed that the accumulation of hmm DNA of pSJS6 was maximal in the lon mutant in a $\operatorname{rec} B C D^{+}$exoI $\mathrm{I}^{+} x t h A^{+}$genetic background.

To further investigate our finding of enhanced accumulation of hmm DNA in a lon mutant of E. coli, we transformed pBR322 plasmid DNA into a lon mutant. DNA was prepared from these cells as described above. Analysis of pBR322 plasmid DNA on agarose gels showed low amounts of plasmid oligomers (Fig. 2). Treatment of pBR322 DNA with EcoRI in the presence of ethidium bromide did indeed convert Form I DNA into Form II DNA; the slow-migrating bands persisted however (compare lanes in the absence and presence of $E c o$ RI and ethidium bromide). To exclude the possibility of selective DNA extraction and to ascertain that the same cell density corresponds to cell number, we extracted and analysed chromosomal DNA from various hosts, harbouring pSJS6, and found that cell density correlates with the amounts of chromosomal DNA in all the strains (data not shown).

\section{Time-dependent synthesis of plasmid multimers}

Total plasmid DNA preparation for the experiment in Fig. 2 was obtained from cultures $3 \mathrm{~h}$ after thermal derepression of red genes. It is, however, possible that the reduced accumulation of plasmid multimers in $\operatorname{rec} A^{+}$ 

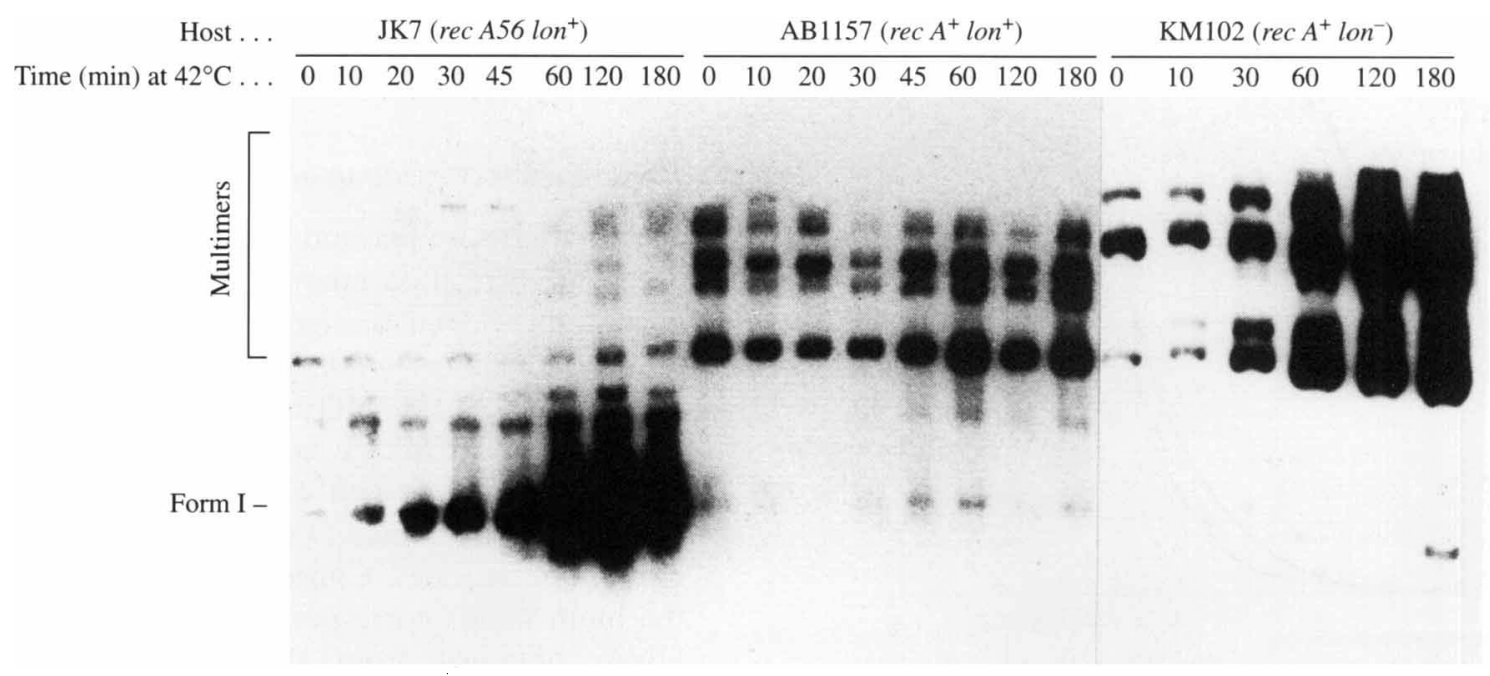

Fig. 3. Time-dependent accumulation of plasmid linear multimers at $42^{\circ} \mathrm{C}$. Exponential phase cells of the indicated genotype, harbouring pSJS6 plasmid DNA, were shifted from $30^{\circ} \mathrm{C}$ to $42^{\circ} \mathrm{C}$. Total plasmid DNA preparations, obtained from cultures $3 \mathrm{~h}$ after thermal derepression of red genes, and taken at the indicated time intervals, was analysed on a $0.5 \%$ agarose gel as described in Methods.

$\operatorname{lon}^{+}$(AB1157) cells may reflect increased degradation of $\mathrm{hmm}$ DNA at earlier times during induction. To test this hypothesis, we compared the kinetics of accumulation of hmm DNA in a set of isogenic strains: recA56 lon $^{+}$ (JK7), rec $A^{+}$lon $^{+}$(AB1157) and rec $A^{+}$lon $^{-}$(KM102). Aliquots of identical numbers of cells were taken after derepression of red genes at various time intervals. Total plasmid DNA was analysed on agarose gels as described above. As illustrated in Fig. 3, the kinetics of accumulation of pSJS6 Form I DNA in the recA56 lon $^{+}$ strain increased until about $2 \mathrm{~h}$. During the initial $60 \mathrm{~min}$ time period, there was virtually no indication of the production of plasmid multimers; however, traces of multimers were detectable after $2 \mathrm{~h}$. The basis for the production of large amounts of Form I DNA in this strain, at present, is unknown. By contrast, a timedependent increase, albeit low, in the amount of multimeric DNA was observed in the $r e c A^{+} l o n^{+}$genetic background, while the $\operatorname{recA^{+}}$ lon $^{-}$strain showed a continuous increase of plasmid multimers during the same time period. The persistence of Form I DNA, although not in substantial amounts, argues that the de novo synthesis of plasmid multimers proceeds through the monomeric form of plasmid DNA. However, it is possible that initial production of multimers may arise from monomers and that further higher multimer synthesis results from recombination between multimers. The presence of large amounts of multimeric DNA prior to the derepression of red genes is intriguing. However, it is not due to the nature of plasmid DNA used for transformation of these strains (see below). The DNA sample(s) used for transformation was isolated from rec $A$ cells, and consisted of Form I DNA as confirmed by agarose gel electrophoresis. The occurrence of plasmid multimers implies that plasmid recombination occurs during the exponential phase of growth prior to the induction of red genes. Insight into this phenomenon was gained during the course of analysis of proteins in cellfree extracts obtained from these strains from various stages of growth. We found that substantial amounts of the products of $r e d \alpha$ and $r e d \beta$ were present in these extracts prior to their induction (data not shown). We propose, therefore, that the presence of multimers in these strains may be a consequence of poor repression of the $P_{L}$ promoter in a multicopy plasmid thereby resulting in the expression of red genes. Nonetheless, the production of plasmid multimers, following the induction of red genes, appears to be a function of incubation at $42^{\circ} \mathrm{C}$.

To relate the dependence of the formation of $\mathrm{hmm}$ DNA to the availability of red functions, we sought to inhibit de novo protein synthesis. Accordingly, we added chloramphenicol $\left(100 \mu \mathrm{g} \mathrm{ml}^{-1}\right)$ to a lon mutant harbouring pSJS6, immediately after thermal derepression of red genes. Total plasmid DNA preparations obtained from identical numbers of cells were resolved on agarose gels and analysed by Southern hybridization. In the absence of chloramphenicol, the production of multimeric DNA increased with time and when the process of translation was inhibited, the relative amount of $\mathrm{hmm}$ DNA uniformly decreased by approximately $2 \cdot 5$-fold (data not shown). Taken collectively, these results suggest that expression of red genes sets the mode of replication from theta to the production of multimers. 


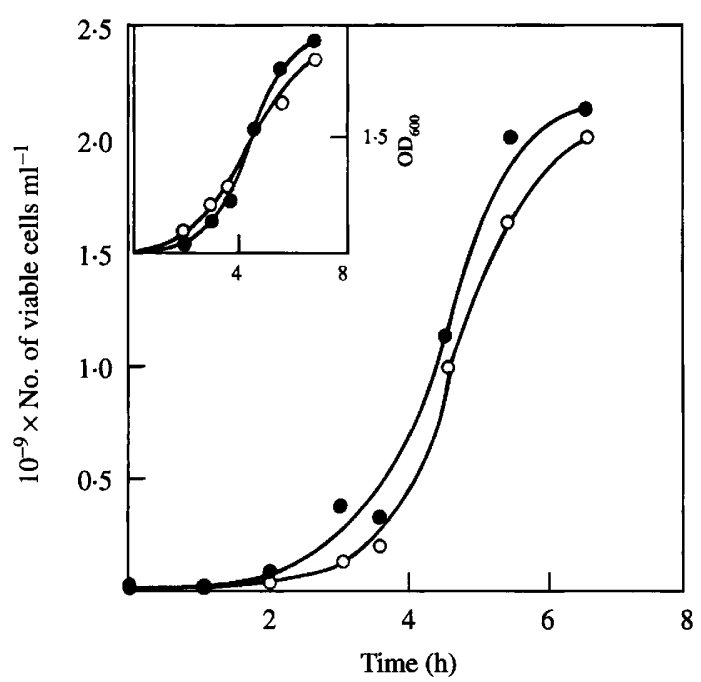

Fig. 4. Lack of association of cell lethality with the formation of plasmid linear multimers promoted by the Red-system of phage lambda. Cultures of exponentially growing cells harbouring pSJS6 were transferred from $30^{\circ} \mathrm{C}$ to $42^{\circ} \mathrm{C}$. At the indicated time intervals aliquots were taken and diluted appropriately and the number of viable cells was determined by plating on L-plates containing the appropriate antibiotics. O, KM102 (recA lon $\left.^{-}\right)$; O $\mathrm{AB} 1157\left(\mathrm{recA}^{+}\right.$lon $\left.^{+}\right)$. Inset, Determination of the total number of cells as monitored by the optical density at $600 \mathrm{~nm}$. 0 , As main figure.

\section{Reduced multimer formation in a rec $A^{+}$lon $^{+}$strain is not attributable to cell lethality}

It has been established that plasmids such as pBR322 and other derivatives from the ColE1 origin lineage are unstable in certain host strains, consequently causing cell death. Most pertinent to this report, however, are the observations dealing with population analyses of bacterial cells producing plasmid multimers resulting in cell lethality (Kusano et al., 1989). Since the magnitude of synthesis of plasmid multimers differs between $\mathrm{recA^{+ }}$ lon $^{+}$ and $\mathrm{recA}^{+} \mathrm{lon}^{-}$genetic backgrounds, it is plausible that the determining factor, following induction of red genes, is the continued viability of cells. Therefore, to gain an insight into the inability of $\mathrm{reA}^{+} \mathrm{lon}^{+}$cells to accumulate hmm DNA, we monitored the growth and viability of cells. In a typical experiment a single-colony transformant of recA $A^{+}$lon $^{+}$(AB1157) and recA $A^{+}$lon $^{-}$(KM102) strains, harbouring pSJS6 were grown in L-broth at $30^{\circ} \mathrm{C}$. When the growth reached mid-exponential phase the cultures were shifted to $42^{\circ} \mathrm{C}$ to facilitate the expression of red genes. Aliquots were removed at different time intervals and total numbers of viable cells were determined on L-plates. As illustrated in Fig. 4, the doubling time as monitored by measuring the density as $\mathrm{OD}_{600}$ (inset) and plating efficiency was identical between recA $A^{+}$lon $^{+}$and $r e c A^{+}$lon $^{-}$strains harbouring pSJS6. These results, therefore, argue that the reduced production of multimeric DNA in the $\mathrm{recA}^{+} \mathrm{lon}^{+}$strain is attributable to the negative effect of lon function and not related to plasmid-mediated host cell lethality.

\section{Further characterization of high molecular mass DNA}

Earlier studies on plasmid recombination have shown an excellent correlation among genetic recombination and generation of circular oligomers of plasmid DNA (Fishel et al., 1981; James et al., 1982). To distinguish between circular and linear multimeric DNA produced by the Red-pathway of phage lambda, purified total plasmid DNA was treated with $E$. coli exonuclease III, which degrades linear duplex DNA from the $3^{\prime}$ ends releasing $5^{\prime}$-mononucleotides. Consequently, as shown in Fig. 5, the $\mathrm{hmm}$ bands corresponding to multimeric forms of DNA, obtained from the $r e c A^{+} l o n^{-}$strain, were significantly reduced in intensity after digestion with exonuclease III, suggesting that the hmm DNA consists of linear multimeric forms. Under these conditions, Form I DNA, which is the major species of DNA present in recA56 lon $^{+}$cells, resisted digestion by exonuclease III (data not shown). Consistent with these results, Silberstein et al. (1990) have also observed by electron microscopy the occurrence of plasmid multimers with free ends, produced by the red genes.

Further physical characterization was done to estimate the size of the multimeric DNA by pulse field gel electrophoresis. The size of plasmid multimers produced by the products of red genes was analysed with a lambda ladder DNA as standard markers (Fig. 6). The bulk of linear plasmid multimers were located between 50 and $240 \mathrm{~kb}$ with a large population of DNA molecules of $100-200 \mathrm{~kb}$ length, which corresponded to more than 10-20 plasmid unit lengths. The electron microscopic analysis of the length of plasmid multimers mediated by the red genes yielded five plasmid unit lengths in the presence of gam function, and when mediated by red genes alone, they were longer than two unit lengths (Silberstein et al., 1990). The reason for this difference in unit length of plasmid multimers, we believe, is a consequence of increased stability, due to the loss of lon function, of enzymes and proteins that promote the formation of multimers.

\section{Production of linear plasmid multimers is abolished in a red $\beta$ mutant}

The foregoing observations have underscored the role of rec $A$ in augmenting the Red-system-promoted synthesis of plasmid multimers. To test whether red $\beta$ is acting in concert with recA (Muniyappa \& Radding, 1986), we constructed a series of nested deletions in $r e d \beta$. For this purpose, we cleaved pSJS6 plasmid DNA, isolated from a recA lon $^{+}$host with Sall (Fig. 1). The linearized DNA 


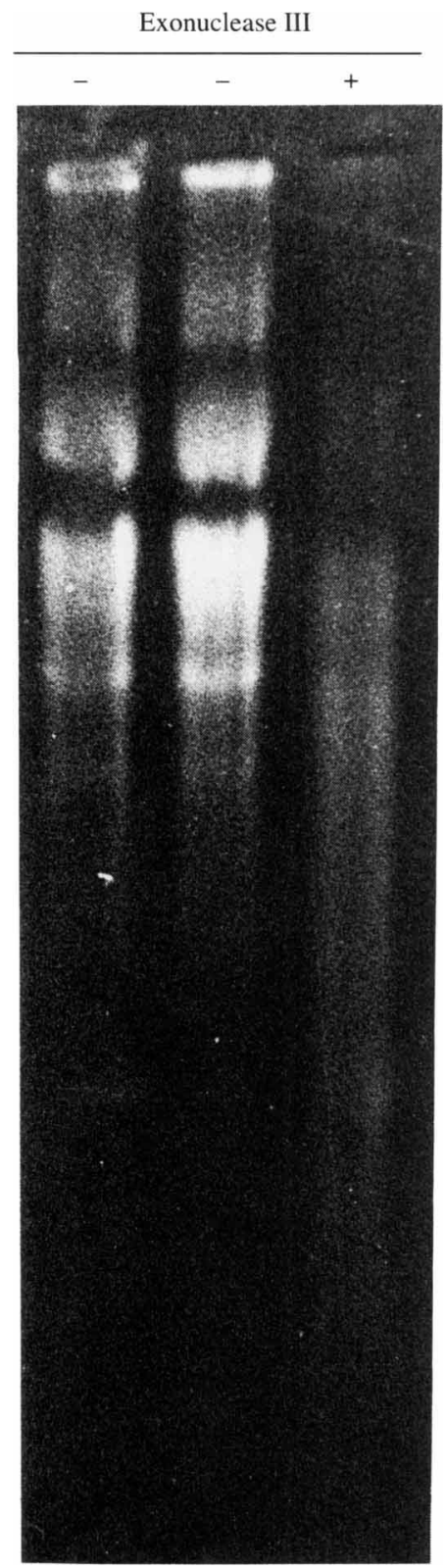

Fig. 5. Plasmid linear multimers produced by the Red-system contain free double-chain ends. Total plasmid pSJS6 DNA, obtained from strain KM102 following induction of red genes, was purified by $\mathrm{CsCl}$ density gradient centrifugation. The DNA was digested by exonuclease III as described in Methods. The samples were resolved on a $0.5 \%$ agarose gel, stained with ethidium bromide and photographed.

was then digested by Bal31 nuclease, for various time periods, and then treated with Klenow to create blunt ends. The DNA was recircularized by ligation and used for transformation of a $r e c A$ strain. Two clones, pKM127.2 and pKM132.9 with deletions of $500 \mathrm{bp}$ and $850 \mathrm{bp}$ in $\mathrm{red} \beta$, were transformed into the $\mathrm{rec}^{+} \mathrm{lon}^{-}$ (KM102) strain. Total plasmid DNA preparations collected from these strains, harbouring the respective constructs, were analysed by electrophoresis and

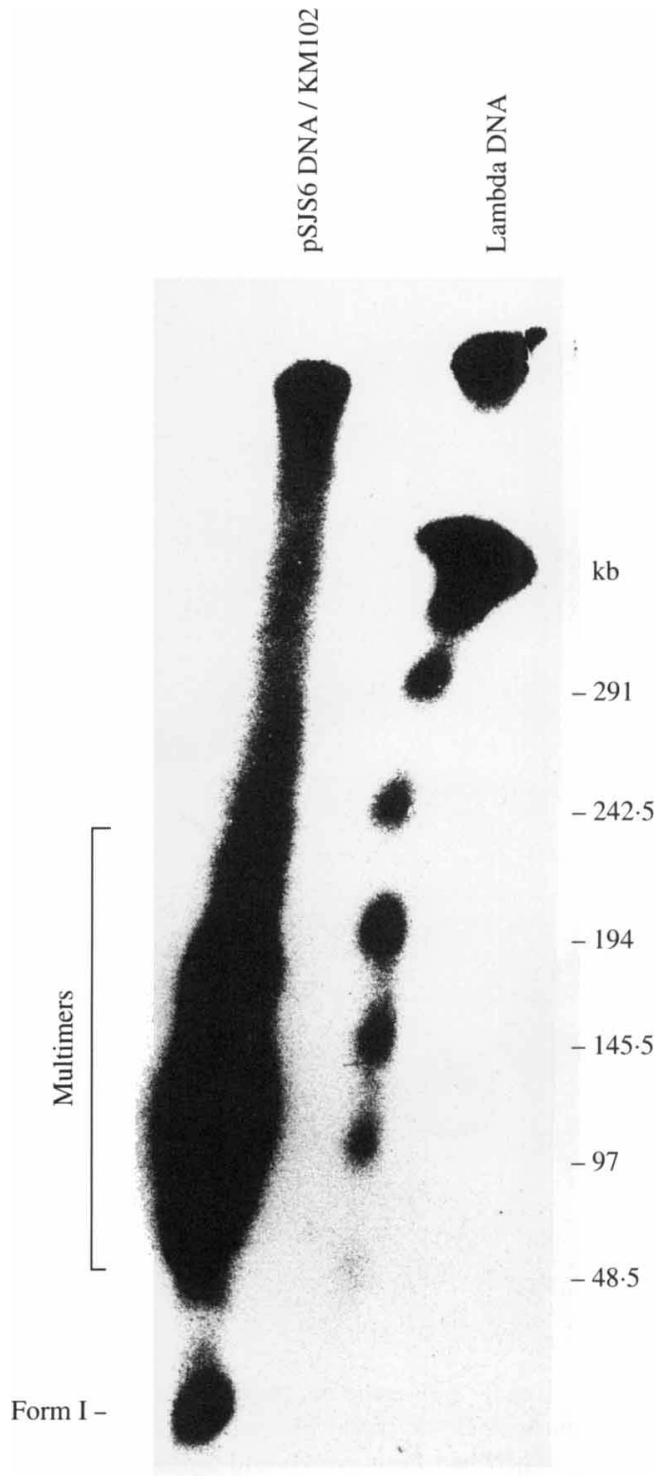

Fig. 6. Determination of the size of plasmid multimers produced by the red genes. Total plasmid DNA was extracted from strain KM102 harbouring pSJS6 and purified by $\mathrm{CsCl}$ density gradient centrifugation. A $2 \mu \mathrm{g}$ amount of purified DNA was used for pulse field gel electrophoresis as described in Methods. The size of the standard markers is indicated on the right.

Southern hybridization as described above. A comparison of the extent of accumulation of plasmid DNA revealed that the wild-type $\operatorname{red} \beta$ produced maximal amounts of multimeric DNA. On the other hand, one of the subsequently constructed deletions in $\operatorname{red} \beta$ (pKM127.2) produced basal levels of multimers of plasmid DNA, while in the DNA preparation obtained from the same strain harbouring pKM132.9, the multimers were completely absent (Fig. 7). These results, therefore, suggest that the production of multimers of plasmid DNA is mediated by recombination and requires the functional red $\beta$ gene product. 


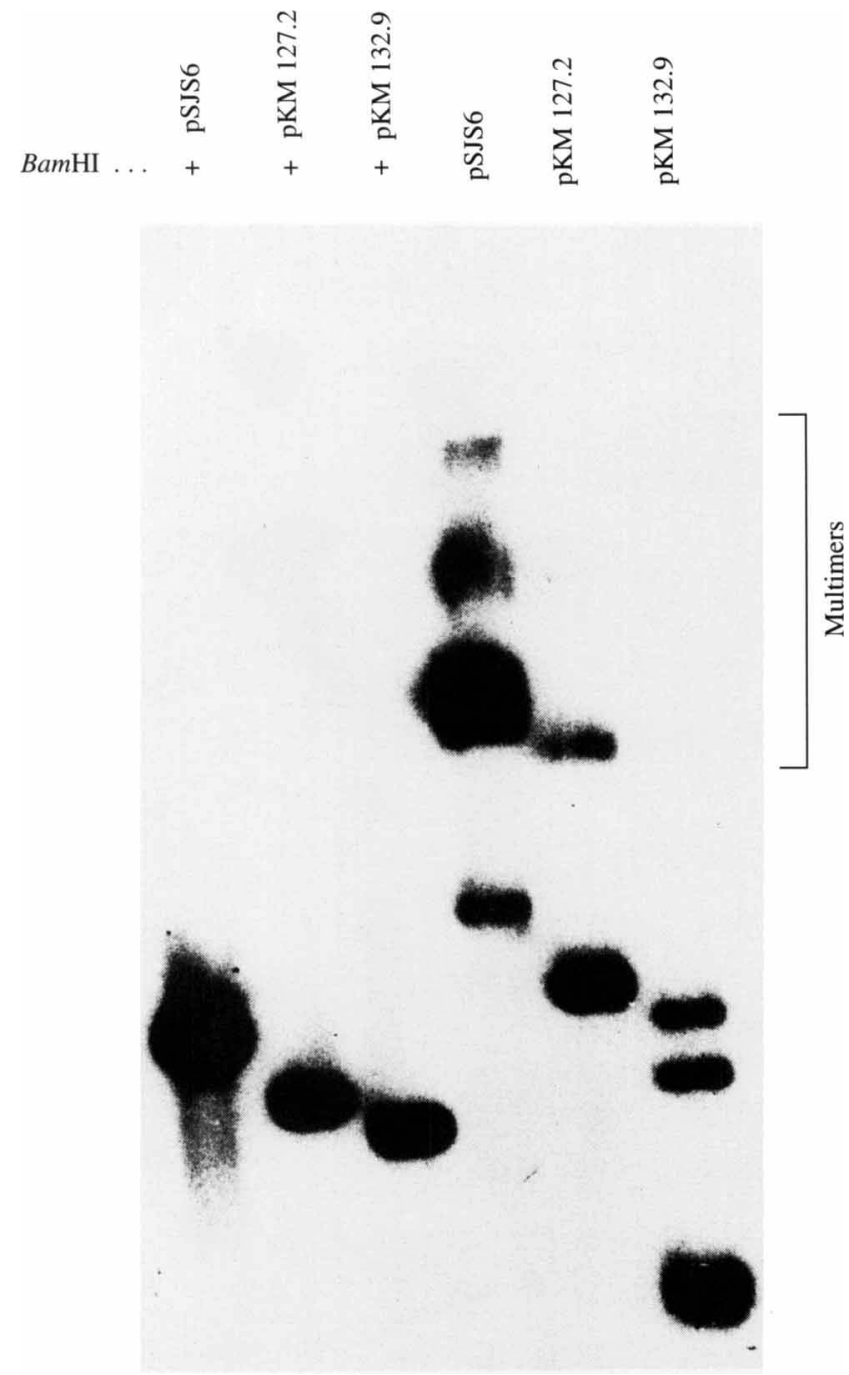

Fig. 7. A functional red $\beta$ gene is required for the formation of multimers of plasmid DNA. Total plasmid DNA was obtained from strain KM102, which had been grown and induced as described, and which harboured the indicated constructs. A portion of total plasmid DNA from each preparation was linearized by BamHI under reaction conditions as described in Methods. The remaining sample of total plasmid DNA was loaded onto an agarose gel and analysed by Southern hybridization.

\section{Discussion}

\section{Action of the RecBC and RecF pathways}

The small circular genomes of bacteriophages and plasmids have provided convenient molecular models for elucidating the genetic requirements and various aspects of the mechanism(s) of homologous genetic recombination. A large number of studies have shown that the oligomerization of circular plasmids in $E$. coli is controlled by host recombination machinery (reviewed in: Smith, 1988; Clark \& Low, 1988; Mahajan, 1988). Studies on the isolated oligomeric forms of DNA have revealed interesting structures such as 'figure-of-eight', the recombination intermediate predicted to occur with circular substrates in both gene conversion and reciprocal exchanges (Fishel et al., 1981; McCarthy, 1982).

The recombination of bacterial plasmid DNA has been studied intensively in various genetic backgrounds in $E$. coli (Cohen \& Clark, 1986; Niki et al., 1990). These studies have shown that plasmids, in wild-type $E$. coli, recombine by a pathway that differs from that of conjugational recombination (Cohen \& Clark, 1986). Mutations in $\operatorname{recB}$ and $\operatorname{rec} C$ alleles which reduce conjugational recombination have no apparent effect on plasmid recombination (Kolodner, 1980). On the other hand, plasmid recombination depends on the functions of $r e c F, r e c J$ and $r e c O$ which participate in $r e c F$ conjugational recombination (Kolodner et al., 1985). This pathway becomes pronounced in $r e c B$ recC $s b c B$ $s b c C$ mutants. The other pathway, the RecE pathway, is activated in $E$. coli cells carrying an $s b c A$ mutation (Clark \& Low, 1988). The RecE pathway is partially coded for by a cryptic lambdoid prophage. Plasmid recombination in these strains occurs with a high efficiency and does not require the $\operatorname{rec} A$ and $\operatorname{rec} F$ gene products (Clark \& Low, 1988). All this information was generated while establishing a correlation among genetic recombination and the formation of circular oligomers and, subsequently, their interconversion into monomers. The exact relationship among the pathways of conjugational recombination and plasmid recombination is unknown. Nonetheless, the studies of James et al. (1982) have revealed that the RecBC recombination pathway produces circular oligomers whereas the $\mathrm{RecF}$ pathway converts them into monomers.

\section{Generation of linear multimers}

A. Cohen and his colleagues discovered yet another mode of plasmid recombination that results in the formation of linear multimers (Cohen \& Clark, 1986; Silberstein \& Cohen, 1987). In wild-type E. coli, inactivation of RecBCD enzyme either by phage lambda gam protein or by mutations in $\operatorname{rec} B$ and $\operatorname{rec} C$ alleles switches the mode of synthesis of plasmids from circular monomers to linear multimers. The production of linear multimers requires not only the activities of the RecF pathway, such as recF, recJ, recN, recO, rec $Q$ and $r u v$ but also the product of the recA gene (James et al., 1982; Kolodner et al., 1985; Kusano et al., 1989). A corollary to this phenomenon exists in recombination-aided replication of the phage lambda chromosome (Skalka, 1977). In wild-type cells, in the presence of a potent RecBCD nuclease, the predominant form of replication is theta-type. Inactivation of RecBCD nuclease diverts phage lambda chromosome replication towards the production of linear multimers by the rolling-circle mode 
of replication. The production of viable phage particles is greatly facilitated with the concomitant activation of Rac prophage, suggesting that DNA replication and recombination are tightly interrelated (Kushner et al., 1974; Joseph \& Kolodner, 1983; Clark \& Low, 1988).

It has been shown by Berger \& Cohen (1987) and Nussbaum \& Cohen (1988) that Red-combination machinery promotes plasmid recombination in $\operatorname{rec} B$ $\operatorname{rec} C \operatorname{sbc} B$ cells in a $\operatorname{rec} A$-independent manner. These studies involved intrachromosomal recombination among heteroalleles of a luciferase gene. Interestingly, those authors have also noted the inability of red functions to promote intraplasmidic recombination in $\mathrm{RecBCD}^{+} \mathrm{ExoI}^{+}$E. coli strains.

\section{Role of red genes in formation of plasmid multimers}

We found that expressions of red genes in $\mathrm{RecBCD}^{+}$ $\mathrm{ExoI}^{+}$ExoIII ${ }^{+}$host cells led to the synthesis of plasmid multimers. Under these conditions, multimer production promoted by the Red-system was higher in $r e c A^{+}$than in recA mutant strains, which are otherwise wild-type for $r e c B, r e c C, s b c B, s b c C$ genes. Recently, Silberstein et al. (1990) have shown that in wild-type strains the production of maximal amounts of plasmid DNA promoted by the Red-system requires gam function. The source of this seemingly conflicting data is unknown at present. Several lines of evidence, however, argue that it is not due to the increased degradation of multimers by RecBCD nuclease. It has been suggested that degradation of DNA substrates and intermediates is not sufficient to cause the return of rolling circle DNA replication to theta-mode of replication (Skalka, 1977). Correspondingly, Kusano et al. (1989) have shown that in $r e c A$ strains there was 100 -fold reduction in the extent of synthesis of multimeric DNA in the absence of $\operatorname{recB}$, $r e c C, s b c B, s b c C$ gene products.

The induction of red genes requires the transfer of cultures from $30^{\circ} \mathrm{C}$ to $42^{\circ} \mathrm{C}$ and such a shift also results in expression of the host Lon protease. We reasoned that Lon protease might play a dominant role by cleaving enzymic machinery that participates in the initiation of plasmid recombination as well as those components that act on the putative recombination intermediates. Consistent with this hypothesis, we observed that the formation of linear multimers, after the induction of red genes, was at least 3-fold higher in lon mutants than in the isogenic $l^{+}{ }^{+}$strains. It is likely, therefore, that Lon protease rapidly destroys the protein components that are processing the labile DNA substrates and intermediates. Furthermore, the finding that the magnitude of Red-promoted plasmid multimer synthesis was higher in the $r e c A^{+}$strain is compatible with our earlier observations that $\beta$ protein acts in concert with RecA protein in

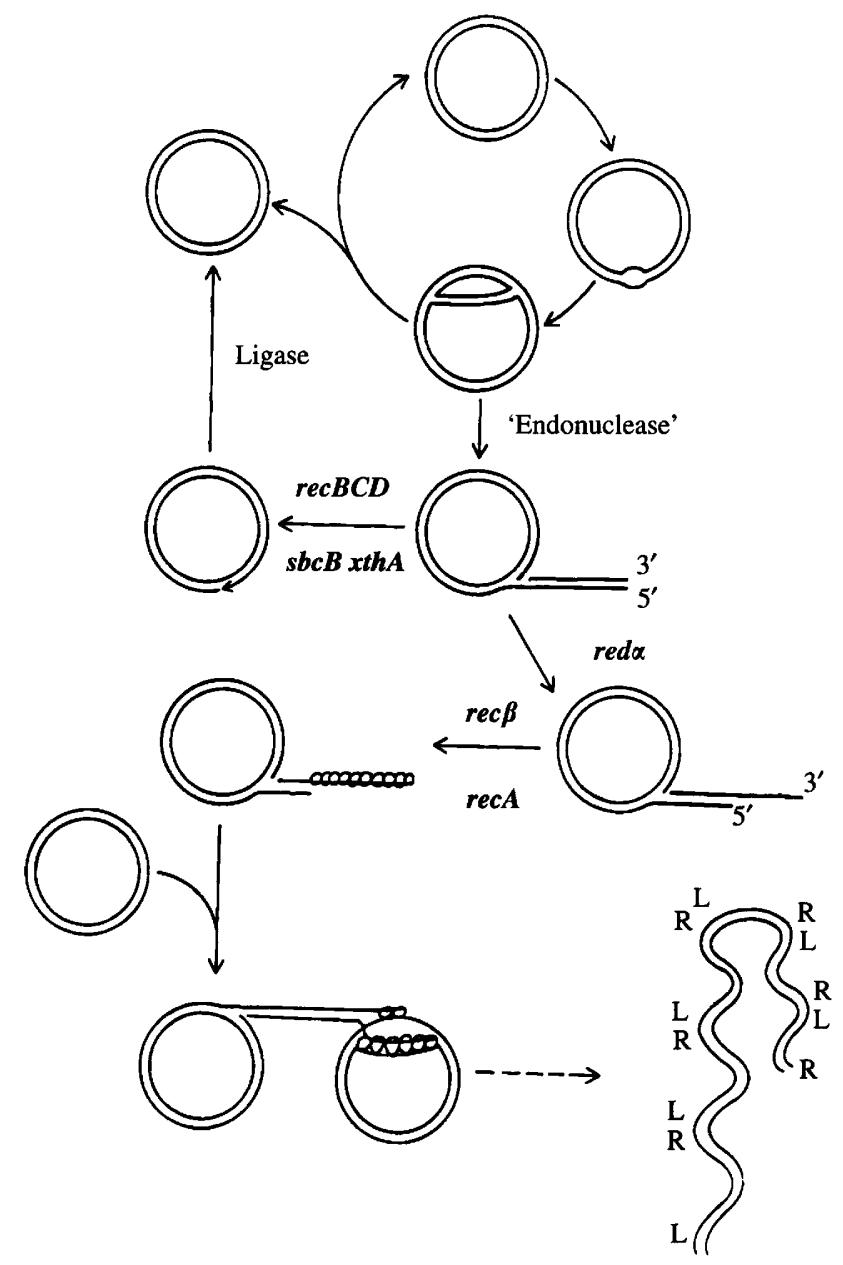

Fig. 8. Diagram depicting a hypothetical path to the formation of plasmid linear multimers promoted by the Red-pathway of phage lambda. For details see Discussion.

the formation of joint molecules (Muniyappa \& Radding, 1986). Our genetic analysis of the negative effect of Lon protease on the formation of plasmid multimers provides intriguing clues as to the interaction of other cellular enzymic activities that regulate homologous recombination and perhaps other processes related to DNA metabolism.

\section{A conceptual framework for the Red-pathway}

To think about how the Red-pathway of phage lambda facilitates the formation and enhanced accumulation of plasmid linear multimers in wild-type as well as in lon mutants of $E$. coli, it is important to consider a conceptual framework that could account for their production (Fig. 8). There appears to be a general agreement that the formation of linear multimers or concatemers is sensitive to the action of $\operatorname{rec} B C D$ xth $A$ $s b c B s b c C$ gene products. The negative effect of lon 
function is partly attributable to its ability to degrade the enzymes and proteins processing the labile DNA substrates and recombination intermediates. There are at least two concerted mechanisms by which such substrates and intermediates could contribute to the formation of linear multimers. The first possibility is the rolling circle replication: we presume that an intermediate in the monomer circle replication is converted into an open circular form by the action of an 'endonuclease'. Mechanisms of the second category include the recombination-dependent or the bubble-migration mode (Formosa \& Alberts, 1986). In such a situation, a 3' single-stranded tail is produced by the action of red $\alpha$, and serves as a substrate for the binding of red $\beta$. The nucleoprotein filament (Muniyappa \& Radding, 1986) thus formed invades a homologous sequence on the circular template. This interpretation parallels in several aspects the production of concatemers during late replication in phage-infected bacterial cells (Skalka, 1977; Stahl et al., 1973). Recently, Silberstein et al. (1990) have provided complementary evidence, by electron microscopy, for the occurrence of two types of molecular structures: sigma-shaped and linear molecules, believed to be the intermediates in the path to the formation of plasmid linear multimers.

In summary, all the experimental evidence and the framework that we have provided is compatible with the notion that double-stranded ends provoke recombination promoted by the Red-pathway (Stahl, 1986; Thaler et al., 1987; Takahashi \& Kobayashi, 1990). Taken collectively, our genetic analysis has revealed that the formation of plasmid multimers is maximal in lon mutants in $\mathrm{RecBCD}^{+} \mathrm{ExoI}^{+} \mathrm{ExoIII}^{+}$proficient host cells. In addition, or more importantly, these new concepts initiate an understanding of the interplay among cellular enzymic machinery related to DNA metabolism and protein degradation in plasmid recombination.

We thank Drs Steven Sandler, John Clark, Amikam Cohen, Charles Radding, Thomas Silhavy, R. Jayaraman and Susan Gottesman for bacterial strains and plasmids; we also thank Dr G. Padmanaban for his continued help and support. We acknowledge Dr Imran Siddiqui for his help in running PFGE and Ms M. V. Bhuvana for technical assistance. This research was funded by grants from the Department of Science and Technology, New Delhi. E. Mythili holds a fellowship from CSIR, New Delhi.

\section{References}

BEDBROOK, R. \& AUSUBEL, F. M. (1976). Recombination between bacterial plasmids leading to the formation of plasmid multimers. Cell 9, 707-716.

BERGER, I. \& CoHEN, A. (1989). Suppression of RecA deficiency in plasmid recombination by bacteriophage lambda beta protein in $\mathrm{RecBCD}^{-}$Exol $^{-}$Escherichia coli cells. Journal of Bacteriology 171, 3523-3529.

Clark, A. J. \& Low, K. B. (1988). Pathways and systems of homologous recombination in Escherichia coli. In The Recombination of Genetic Material, pp. 155-215. Edited by K. B. Low. New York: Academic Press.

COHEN, A. \& ClARK, A. J. (1986). Synthesis of linear plasmid multimers in Escherichia coli K-12. Journal of Bacteriology 167, 327-335.

DoherTy, M. J., Morrison, P. T. \& Kolodner, R. (1983). Genetic recombination of bacterial plasmid DNA. Physical and genetic analysis of the products of plasmid recombination in Escherichia coli. Journal of Molecular Biology 167, 539-560.

ENQUisT, L. W. \& SKalKA, A. (1973). Replication of bacteriophage lambda DNA dependent on function of host and viral genes. I. Interaction of red, gam and rec. Journal of Molecular Biology 75, 185-212.

Fishel, R. A., James, A. A. \& Kolonner, R. (1981). rec A-independent general genetic recombination of plasmids. Nature, London 294, $184-186$.

Formosa, T. \& AlBerTs, B. M. (1986). DNA synthesis dependent on genetic recombination: characterization of a reaction catalyzed by purified bacteriophage T4 proteins. Cell 47, 793-806.

GotTESMAN, S. (1989). Genetics of proteolysis in Escherichia coli. Annual Review of Genetics 23, 163-198.

Greenstein, M. \& Skalka, A. (1975). Replication of bacteriophage lambda DNA: in vivo studies of the interaction between the viral gamma protein and host RecBC DNase. Journal of Molecular Biology 97, 543-559.

Harashima, S., Shimada, Y., Nakade, S. \& Oshima, Y. (1989). Plasmid multimerization is dependent on RAD52 activity in Saccharomyces cerevisiae. Molecular and General Genetics 219, 495-498.

James, A. A., Morrison, P. T. \& Kolodner, R. (1982). Genetic recombination of bacterial plasmid DNA. Analysis of the effect of recombination deficient mutations on plasmid recombination. Journal of Molecular Biology 160, 411-430.

JAMES, A. A., MORRISON, P. T. \& KoloDNER, R. (1983). Isolation of genetic elements that increase frequencies of plasmid recombinants. Nature, London 303, 256-259.

JOSEPH, J. W. \& KOLODNER, R. (1983). Exonuclease VIII of Escherichia coli. II. Mechanism of action. Journal of Biological Chemistry 258, 10418-10424.

KarU, A., SAKAKI, Y. \& Echols, H. (1975). The gam protein specified by phage lambda: structure and inhibitory activities for RecBC enzyme of Escherichia coli. Journal of Biological Chemistry 250, 7377-7387.

KOLODNER, R. (1980). Genetic recombination of plasmid DNA: electron microscopic analysis of in vitro intramolecular recombination. Proceedings of the National Academy of Sciences of the United States of America 77, 4847-4851.

Kolodner, R., FisHel, R. A. \& Howard, M. (1985). Genetic recombination of bacterial plasmid DNA: effect of RecF-pathway mutations on plasmid recombination in Escherichia coli. Journal of Bacteriology 163, 1060-1066.

Kusano, K., Nakayama, K. \& Nakayama, H. (1989). Plasmid mediated lethality and plasmid multimer formation in an Escherichia coli $\operatorname{rec} B C$ sbcBC mutant: involvement of $\mathrm{RecF}$ recombination pathway genes. Journal of Molecular Biology 209, 623-634.

Kushner, S. R., Nagaishi, H. \& Clark, A. J. (1974). Isolation of exonuclease VIII: the enzyme associated with the $s b c A$ in direct suppressor. Proceedings of the National Academy of Sciences of the United States of America 71, 3593-3597.

LuRIA, S. E. \& Burrous, J. W. (1957). Hybridization between Escherichia coli and Shigella. Journal of Bacteriology 74, 461-476.

MCCARTHY, D. (1982). Plasmid recombination in Haemophilus influenzae. Journal of Molecular Biology 157, 577-596.

Mahajan, S. (1988). Pathways of homologous recombination in Escherichia coli. In Genetic Recombination, pp. 87-140. Edited by R. Kucherlapati \& G. R. Smith. Washington, DC: American Society for Microbiology.

Maniatis, T., Fritsch, E. F. \& Sambrook, J. (1982). Molecular Cloning: A Laboratory Manual. Cold Spring Harbor, NY: Cold Spring Harbor Laboratory.

Miller, J. H. (1972). Experiments in Molecular Genetics. Cold Spring Harbor, NY: Cold Spring Harbor Laboratory. 
MuniyapPa, K. \& Radding, C. M. (1986). The homologous recombination system of phage lambda: pairing activities of beta protein. Journal of Biological Chemistry 261, 7472-7478.

Niki, H., Ogura, T. \& Hiraga, S. (1990). Linear multimer formation of plasmid DNA in Escherichia coli hopE (recD) mutants. Molecular and General Genetics 224, 1-9.

Nussbaum, A. \& COHEN, A. (1988). Use of bioluminescence gene reporter for the investigation of Red-dependent and Gam-dependent plasmid recombination in Escherichia coli K-12. Journal of Molecular Biology 203, 391-402.

Rould, E., MuniYAPPA, K. \& RADDING, C. M. (1992). Unwinding of heterologous DNA by RecA protein during the search for homologous sequences. Journal of Molecular Biology 226, 127-139.

SANDLER, S. J. \& ClaRK, A. J. (1990). Factors affecting expression of the $r e c F$ gene of Escherichia coli K-12. Gene 86, 35-43.

SilbersteIn, Z. \& CoHEN, A. (1987). Synthesis of linear multimers of oriC and pBR322 derivatives in $E$. coli $\mathrm{K}-12$ : role of recombination and replication functions. Journal of Bacteriology 169, 3131-3137.

Silberstern, Z., MaOR, S., Berger, I. \& Cohen, A. (1990). Lambda Red-mediated synthesis of plasmid linear multimers in Escherichia coli K-12. Molecular and General Genetics 223, 496-507.

SkALKA, A. (1977). DNA replication - bacteriophage lambda. Current Topics in Microbiology and Immunology 78, 201-237.

SMITH, G. R. (1988). Homologous recombination in prokaryotes. Microbiological Reviews 52, 1-28.

SOUTHERN, E. M. (1975). Detection of specific sequences among DNA fragments separated by gel electrophoresis. Journal of Molecular Biology 98, 503-517.

STAHL, F. W. (1986). Roles of double strand breaks in generalized genetic recombination. Progress in Nucleic Acid Research and Molecular Biology 33, 169-194.
STAHL, F. W. \& STAHL, M. M. (1974). Red-mediated recombination in bacteriophage lambda. In Mechanisms of Recombination, pp. 407-409. Edited by R. Grell. New York: Plenum Press.

Stahl, F. W., McMilin, K. D., Stahl, M. M., Malone, R. E., Nozu, Y. \& Russo, V. E. A. (1972). A role for recombination in the production of "freeloader" lambda bacteriophage particles. Journal of Molecular Biology 68, 57-67.

Stahl, F. W., Chung, S., Crasemann, J., Fauld, D., Halmer, J., Lam, S., Malone, R., McMilin, K., NozU, Y., Siegel, J., Strathern, J. \& Stahl, M. M. (1973). Recombination replication and maturation in phage lambda. In Virus Research, pp. 487-496. Edited by C. Fox \& W. Robinson. New York: Academic Press.

Symington, L. S., Fogarty, L. M. \& Kolodner, R. (1983). Genetic recombination of homologous plasmids catalyzed by cell-free extracts of Saccharomyces cerevisiae. Cell 35, 805-813.

TAKAHASHI, N. \& KOBAYASHI, I. (1990). Evidence for the double-strand break repair model of bacteriophage lambda recombination. Proceedings of the National Academy of Sciences of the United States of America 87, 2790-2794.

Thaler, D. S., Stahl, M. M. \& Stahl, F. W. (1987). Tests of the double strand break repair model for Red-mediated recombination of phage lambda and plasmid lambda dv. Genetics 166, 501-511.

UNGER, R. C. \& CLARK, A. J. (1972). Interaction of the recombination pathways of bacteriophage lambda and its host Escherichia coli $\mathrm{K}$ 12: effect on exonuclease V activity. Journal of Molecular Biology 70, $539-548$.

Willetts, N. S., Clark, A. J. \& Low, B. (1969). Genetic location of certain mutations conferring recombination deficiency in $E$. coli. Journal of Bacteriology 97, 244-249.

YARMOLINSKY, M. B. \& STERNBERG, N. (1988). Bacteriophage P1. In The Bacteriophages, vol. 1, pp. 291-308. Edited by R. Calender. New York: Plenum Press. 